Journal of Advanced Research in Fluid Mechanics and Thermal Sciences

\title{
Aerodynamic Performance Enhancement of Electromagnetic Gun Projectile Using Numerical Techniques
}

\author{
Fariha Rahman ${ }^{1}$, Srinivas G. ${ }^{2, *}$ \\ 1 Department of Aeronautical and Aviation Science and Engineering, College of Aviation Technology affiliated with National University of \\ Bangladesh, Gazipur, Dhaka-1230, Bangladesh \\ 2 Department of Aeronautical and Automobile Engineering, Manipal Institute of Technology, Manipal Academy of Higher Education (MAHE) \\ Manipal - 576104. Karnataka, India
}

\section{ARTICLE INFO ABSTRACT}

\section{Article history:}

Received 24 October 2020

Received in revised form 1 February 2021

Accepted 5 February 2021

Available online 3 March 2021

\section{Keywords:}

Gun; projectile; aerodynamic; CFD; analysis; turbulence

\begin{abstract}
The unique study named aerodynamic performance enhancement of electromagnetic (EM) gun Projectile using numerical techniques is adopted to determine the better understanding of its aerodynamic characteristics. The earlier studies on EM gun projectile could explore its aerodynamic stability during flight whereas this unique research explains the enhancement of aerodynamic performance of EM gun projectile using numerical techniques. By using the Navier-Stokes numerical approach for a steady-state compressible flow, the Computational Fluid Dynamics (CFD) simulation of density, pressure, and temperature flow contours of the EM gun projectile flow field at different Mach number- 5 to 10 with an increment of 0.5 at zero angle of attack (AOA) have been analyzed. The results show an excellent agreement for the Mach numbers 5, 6, and 7. Moreover, to ensure accurate knowledge of the aerodynamic performance of EM gun projectile the numerical test is conducted several times using different turbulence models and differing the grid element sizes for Mach number 7. The results prove that at hypersonic speed the EM gun projectile performs in a much better way at Mach number 7. This best performance is analyzed by using the Spalart Allmaras (SA) turbulence model for grid size $5.4169 \mathrm{e}-03 \mathrm{~m}$. This work will help the researchers to do further improvements in EM gun projectile aerodynamic behaviors and also can be useful for military purposes.
\end{abstract}

\section{Introduction}

An Electromagnetic (EM) railgun is a unique type of weapon that uses the electromagnetic force to accelerate a projectile at an incredible high velocity more than $2500 \mathrm{~m} / \mathrm{s}$ [1]. The main purpose of this EM gun is to be use as weaponry [2]. Besides, using for military applications, NASA has proposed to use a railgun to launch "wedge-shaped aircraft with scramjets" to high-altitude at Mach 10, where fire a small payload into orbit will be fired by them using conventional rocket propulsion [3]. Generally, a rail gun works on the principle the same as the Homopolar motor. It has

\footnotetext{
* Corresponding author.

E-mail address: srinivas.g@manipal.edu
}

https://doi.org/10.37934/arfmts.80.2.136152 
two parallel conducting rails with a sliding armature between them [4]. The armature is propelled by a high-amplitude current - (sometimes more than a million amps) which induces an electric field normal to the current flow direction. The magnetic field causes a Lorentz force which accelerates the projectile with a high velocity [4]. The better flow aerodynamics on delta wing, paper planes and related understanding related aerodynamics very much discussed by Ismail et al., and Tajuddin et al., $[5,6]$.

The study of the aerodynamics of a hypersonic EM gun is the most important thing for designing at the stable configuration and improving the overall performance of the projectile system [7]. That is why the prediction of projectile flight performance is very significant especially for the hypersonic Electromagnetic gun. The major issue with the EM gun projectile is it needs a huge amount of energy to convert electrical energy into kinetic energy.

Recently, Young and David [8] studied the laminar and turbulent computation of a segment projectile under unsteady hypersonic aerodynamic flow conditions.

Another research was done by Xu et al., [9] to analyze the necessary influences of the projectile parameters on the opening characteristics. In this study, they ameliorated a model to predict the opening diameter. In these circumstances, a dimensional analysis, a penetration test of jacket material strength, jacket wall thickness, filling material strength, and numerical modeling and simulation were executed to analyze the parameters of the projectile. Furthermore, Tang et al., studied the ballistic control and projectile rotation in a novel railgun to justify that the newly designed railgun can launch the projectile rotating and to ensure the flight stability [10]. A viscous Computational Fluid Dynamics (CFD) approach to understanding the aerodynamic performance of projectiles in supersonic flight was used by Weinacht [11]. Naik discussed a stability criterion for a subscribed projectile that was based on Lyapunov's second method [12]. In an article, a CFD study of a finned projectile with micro-flaps was analyzed by Sahu [13]. Weinacht used a viscous CFD approach to predict the aerodynamic behavior of projectile at supersonic flight which represented the capability for predicting the linear aerodynamics for the high speed, low AOA flight of aerodynamically smooth axisymmetric projectiles [14]. Unsteady aerodynamics which is associated with the free flight for finned projectiles at supersonic speed by CFD means that was computed by Sahu and it contains advanced time-accurate Navier Stokes technique [15]. Some numerical experiments were carried out using common CFD codes to analyze aerodynamic heating of a hypersonic projectile by Yadav [16]. The remaining gaps in computational fluid dynamics (CFD) technology with an emphasis on hypersonic flow modeling was evaluated by Maicke et al., [17].

The main novelty of this paper is to study the aerodynamic flow behavior and performance enhancement of EM gun projectile under different Mach conditions, under different operating flow conditions, and also testing with the different turbulence models. The famous Navier-Stokes numerical approach used for a steady-state compressible flow, the CFD simulation of density, pressure and temperature flow contours of the EM gun projectile flow field at different Mach number 5 to 10 with an increment of 0.5 at zero AOA have been analyzed. The results show an excellent agreement for the Mach numbers 5, 6, and 7. This study would be very helpful for future research on EM gun projectile performance developments.

\section{Methodology}

In this paper, the aerodynamic behaviours and performance of Electromagnetic gun projectile are analyzed using the CFD approach for different cases. To predict the aerodynamic characteristics and flow simulation, computational numerical approaches have been used accordingly. The numerical computation solutions are described in the below sections were useful enough to 
compute the aerodynamic behaviours i.e. pressure, density, velocity, temperature, and the aerodynamic coefficients of the EM gun projectile [14] .

\subsection{Geometry}

A proper 3D geometry of EM gun projectile is shown in Figure 1 having a length of $5.70904 \mathrm{~mm}$ and area $10.36 \mathrm{~mm}^{\wedge} 2$, as well as a slot angle of 90 degrees, was completed using ANSYS 19.2 design modular. The layout of the EM gun projectile in the Figure 2 shows different parts of the projectile including nose length in slot length [ls1+ls2] and the cylinder length Ic. The geometrical details of the gun projectile are presented in Table 1 properly.

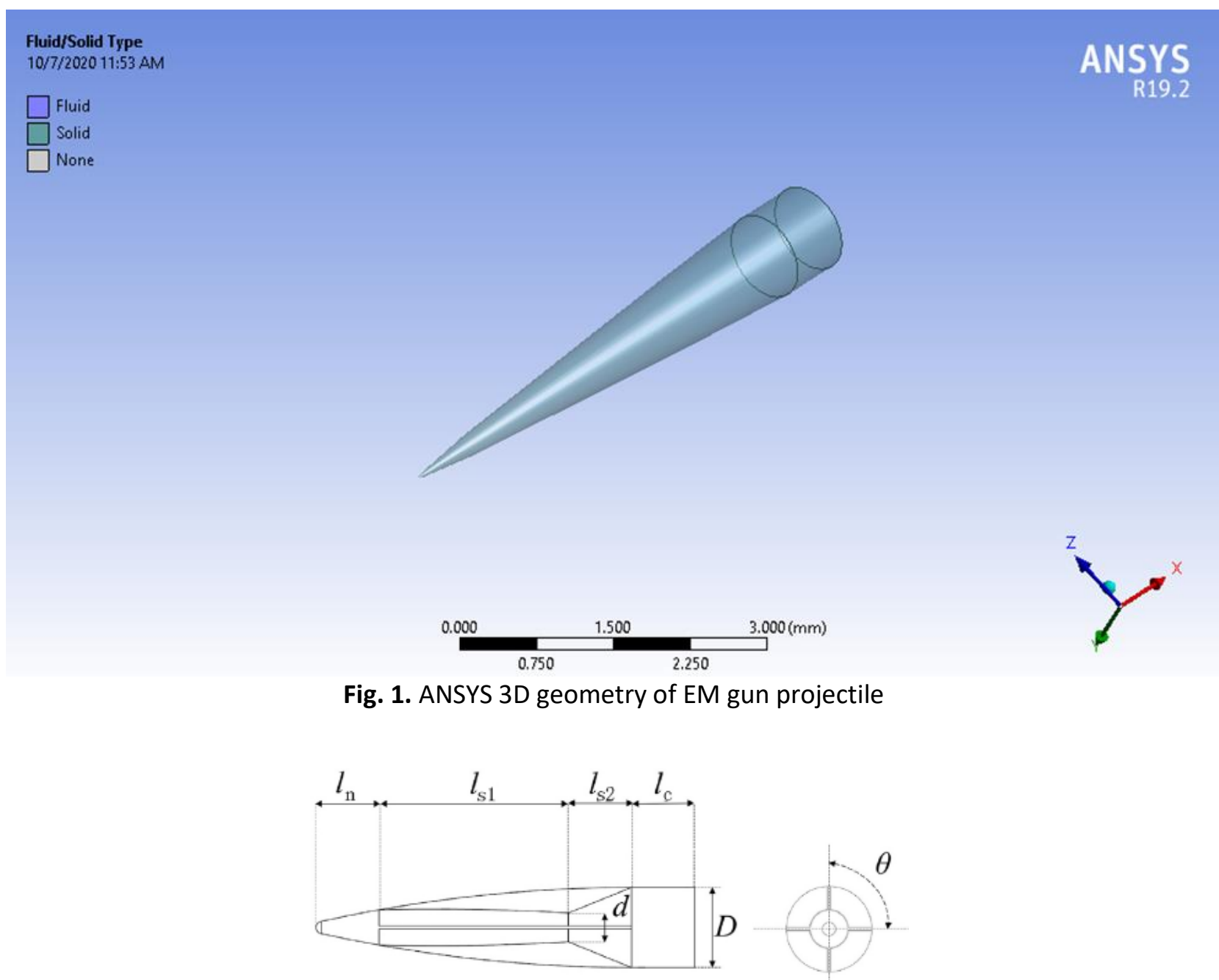

Fig. 2. EM gun projectile layout [1]

Table 1

Details of projectile geometry [1]

\begin{tabular}{ll}
\hline Description & Values \\
\hline Projectile Length [L1+L2] & {$[5.154 \mathrm{~mm}+0.65215 \mathrm{~mm}=5.70904 \mathrm{~mm}]$} \\
Projectile Area & $10.366 \mathrm{~mm}^{\wedge} 2$ \\
Angle & 90 degree \\
\hline
\end{tabular}




\subsection{Meshing}

The CFD domain and an unstructured mesh grid of the gun projectile containing about $3.098 \mathrm{M}$ of mesh elements were created using the ANSYS tool. To make the unstructured mesh more defined and to improve its resolution the automatic mesh method and mesh refinement-1 (for 12 faces and a body) were used as mesh control. A far-field of $30 \mathrm{~mm}$ was created enclosing the projectile. The details about the mesh procedure that was done for the projectile is shown in Table 1. The high-resolution full grid view and close grid view of the EM gun projectile are presented in Figure 3.

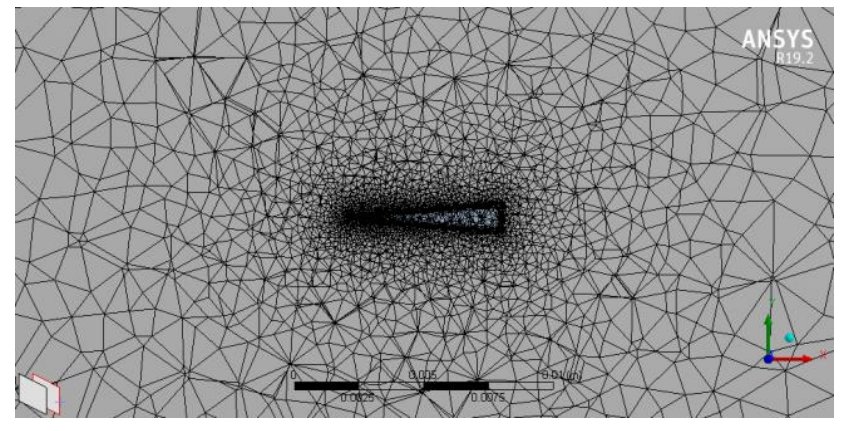

(a)

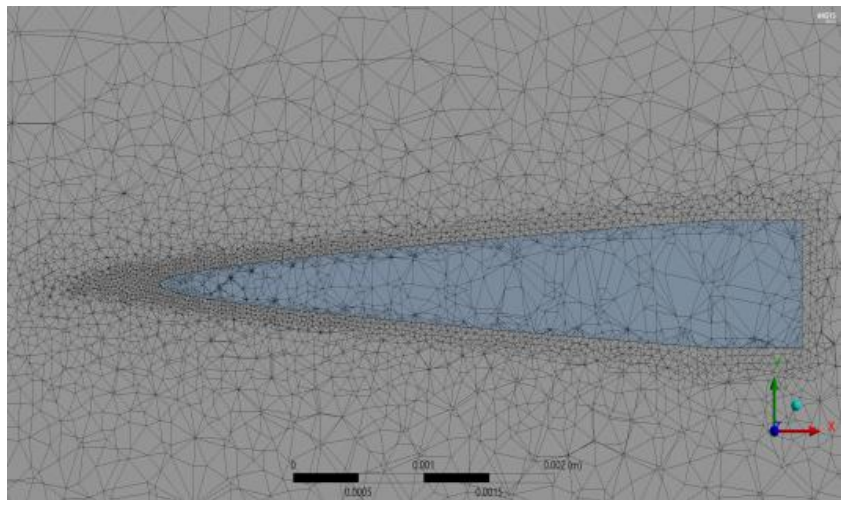

(b)

Fig. 3. Unstructured mesh (a) full grid view and (b) close grid view

\subsection{Numerical Solution Analysis}

In this study, ANSYS Fluent was used to calculate the numerical simulation taking the secondorder upwind, implicit, Roe- FDS to capture the shock wave in hypersonic airflow. To solve the compressible flow a density-based solver was used [14]. For the boundary conditions pressure farfield and pressure outlet was used for the inlet and outlet respectively which produced free stream Mach number and static parameters. The freestream dynamic pressure and outlet pressure were set to be $50 \mathrm{kPa}$ and $2.587 \mathrm{kPa}$ respectively as well as the thermal condition was set to be $221.3 \mathrm{~K}$. Table 2 and Table 3 describe details of the boundary condition that were used in the experiment.

Table 2

\begin{tabular}{ll} 
Solution details & \\
\hline Names & Details \\
\hline General & Density based \\
Energy & On \\
Turbulence model & Spalart Allmaras turbulence model \\
\hline Boundary condition & \\
\hline $\begin{array}{l}\text { Inlet } \\
\text { Outlet }\end{array}$ & Pressure far field \\
Rest of the element & Pressure outlet \\
\hline
\end{tabular}

To compute the most accurate performance numerous case were solved using four turbulence models [namely Spalart Allmaras(SA), K-epsilon (K-e), K-omega (K-w) realizable, and large eddy simulations (LES) [15] were tested for different Mach numbers i.e. Mach- 5 to 10 with the accession of 0.5 [18]. Among the four turbulence models as Spalart Allmaras (SA) model solves one transonic equation for eddy viscosity that gives quite acceptable results for a wide range of flow issues and 
other numerical properties [19]. That is why the SA turbulence model carries great importance to predict the boundary layer that is induced because of the interaction between the turbulence boundary layer and shocks were during the hypersonic flow. In this study, the SA turbulence model has been applied due to its better performance in boundary simulation [20]. The simulations were computed using Intel[R] Core[TM] i5-104000 CPU $2.90 \mathrm{GHz}$, total 6 logical processors and it took 57s CPU time per iteration. A total of 1400 iterations have been done in this regard.

Table 3

CFD conditions to analyze the aerodynamics of EM gun projectile

\begin{tabular}{ll}
\hline Conditions & Parameters \\
\hline Inlet Gauge pressure & $50 \mathrm{kPa}$ \\
Outlet pressure & $2.857 \mathrm{kPa}$ \\
Temperature & $221.3 \mathrm{~K}$ \\
Mach number & 7 \\
Inlet velocity & $2380 \mathrm{~m} / \mathrm{s}$ \\
Air density & Ideal gas law \\
Viscosity & Constant \\
Solution method & 2 nd order upwind for flow and viscosity \\
Courant number used in solution control & 0.5 \\
\hline
\end{tabular}

\section{Computational Fluid Dynamics (CFD) Equations}

In this study, Navier-Stokes equations along with the Spalart Allmaras turbulence model were used to conduct the numerical analysis for compressible hypersonic EM gun projectile aerodynamics. The most general single-phase fluid flow was provided by the Navier-Stokes equations $[21,22]$. The Navier-Stokes equations in a Cartesian form which were used in CFD analysis are as follows from Eq. (1)-(6).

Continuity equation

$\frac{\partial \rho}{\partial t}+\frac{\partial(\rho u)}{\partial x}+\frac{\partial(\rho v)}{\partial y}+\frac{\partial(\rho w)}{\partial z}=0$

$x$ momentum equation

$\rho \frac{\partial u}{\partial t}+\rho u \frac{\partial(u)}{\partial x}+\rho v \frac{\partial(u)}{\partial y}+\rho w \frac{\partial(u)}{\partial z}=-\frac{\partial p}{\partial x}$

y momentum equation

$\rho \frac{\partial v}{\partial t}+\rho u \frac{\partial(v)}{\partial x}+\rho v \frac{\partial(v)}{\partial y}+\rho w \frac{\partial(v)}{\partial z}=-\frac{\partial p}{\partial y}$

z momentum equation

$\rho \frac{\partial w}{\partial t}+\rho u \frac{\partial(w)}{\partial x}+\rho v \frac{\partial(w)}{\partial y}+\rho w \frac{\partial(w)}{\partial z}=-\frac{\partial p}{\partial z}$ 
Energy

$\frac{\partial s}{\partial t}+u \frac{\partial(s)}{\partial x}+v \frac{\partial(s)}{\partial y}+w \frac{\partial(s)}{\partial z}=0$

For a calorically perfect gas Eq. (5) can be replaced by the following equation

$\frac{\partial}{\partial t}\left(\frac{p}{\rho^{\gamma}}\right)+u \frac{\partial}{\partial x}\left(\frac{p}{\rho^{\gamma}}\right)+v \frac{\partial}{\partial y}\left(\frac{p}{\rho^{\gamma}}\right)+w \frac{\partial}{\partial z}\left(\frac{p}{\rho^{\gamma}}\right)=0$

where $\mathrm{u}, \mathrm{v}, \mathrm{w}$ are fluid velocity vectors, $\mathrm{P}$ is pressure, $\rho$ is density, $\mu$ is kinematic viscosity and $\nabla^{2}$ is a Laplacian operator.

\section{Results and Discussion}

The results obtained by this experiment were compared with the experimental data of the paper that is mentioned in reference [1].

\subsection{Baseline Results Analysis}

The flow simulation contours at Mach number-5, 6, and 7 and zero AOA are presented in this section. While analyzing the flow contours some minor differences were indicated between Mach number-5, 6, and 7 in Figure 4. A clear high-pressure region that occurred at the nose of the projectile is presented by the figures. Besides a decrease in the shock angle was identified with the increase of Mach number showing that the shock reached much closed to the airframe as the Mach number increased. Again low density can be seen at the bottom and Baseline.

Figure 5 describes the external maximum pressures on the projectile nose were $4.667 \times 10^{\wedge} 5 \mathrm{~Pa}$, $5.965 \times 10^{\wedge} 5 \mathrm{~Pa}$, and $7.388 \times 10^{\wedge} 5 \mathrm{~Pa}$ at Mach 5,6 , and 7 respectively.

The high pressured zone can be identified by the circular cone areas of the projectile nose. The freestream velocity at different Mach numbers and zero AOA are represented by Figure 6 . The lowspeed region at Baseline and other flow features are presented in these figures. 


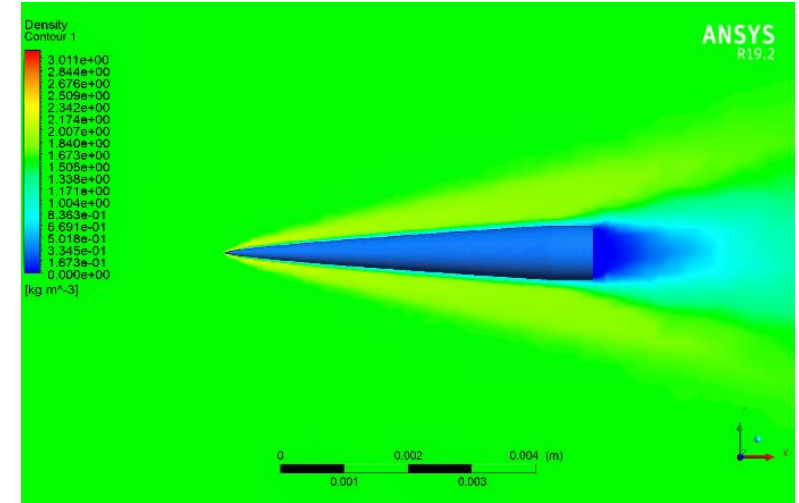

(a)

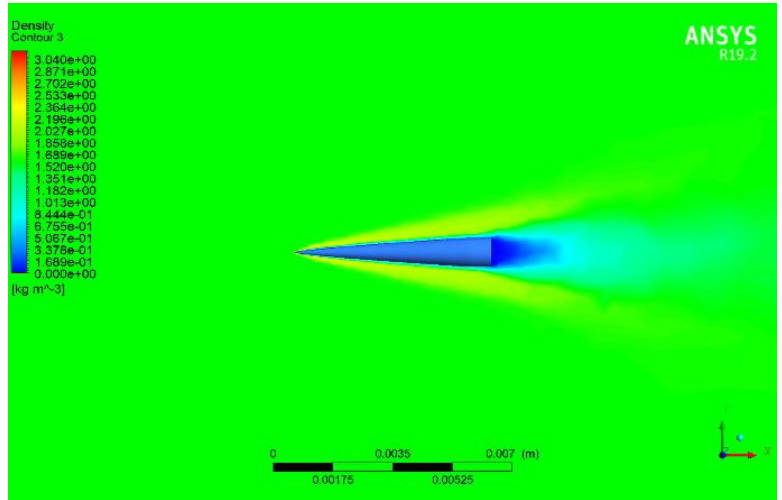

(b)

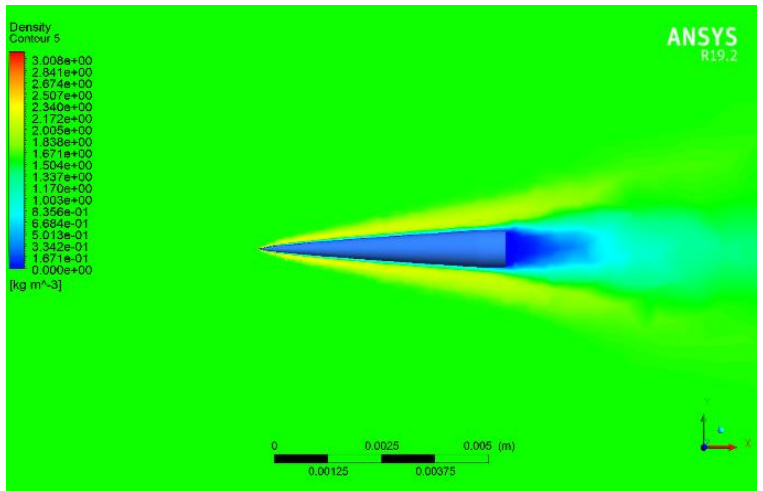

(c)

Fig. 4. Density flow contours at (a) Mach number 5 (b) Mach number 6 and (c) Mach number 7

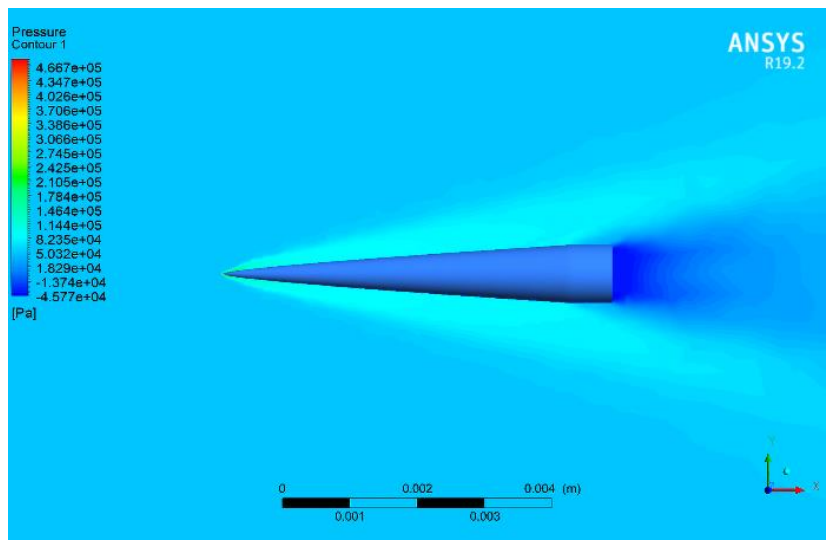

(a)

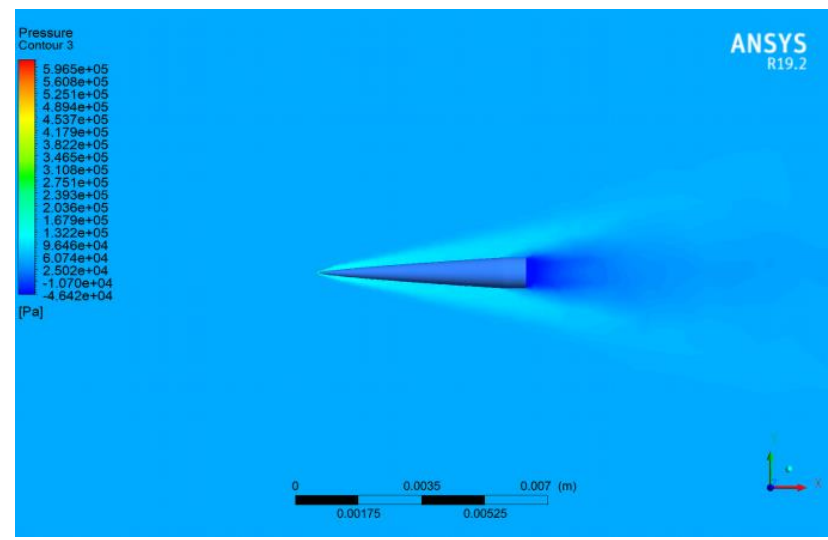

(b)

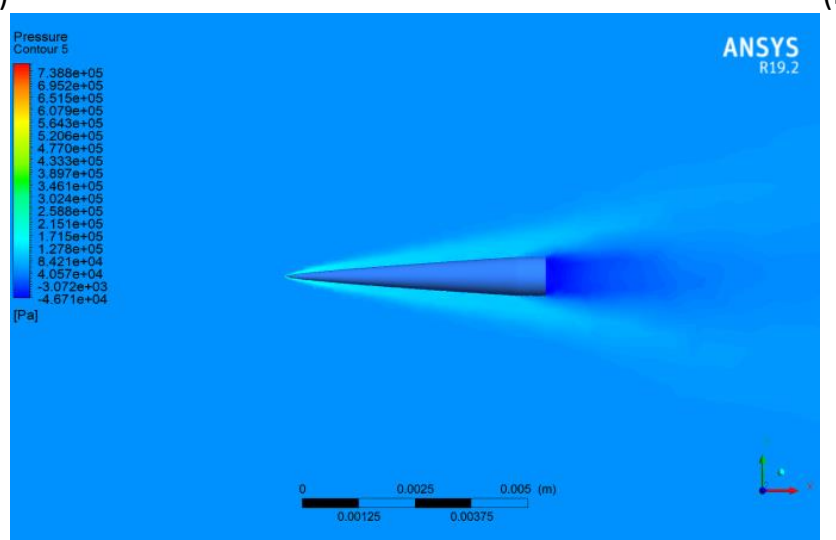

(c)

Fig. 5. Pressure flow contours at (a) Mach number 5 (b) Mach number 6 and (c) Mach number 7 


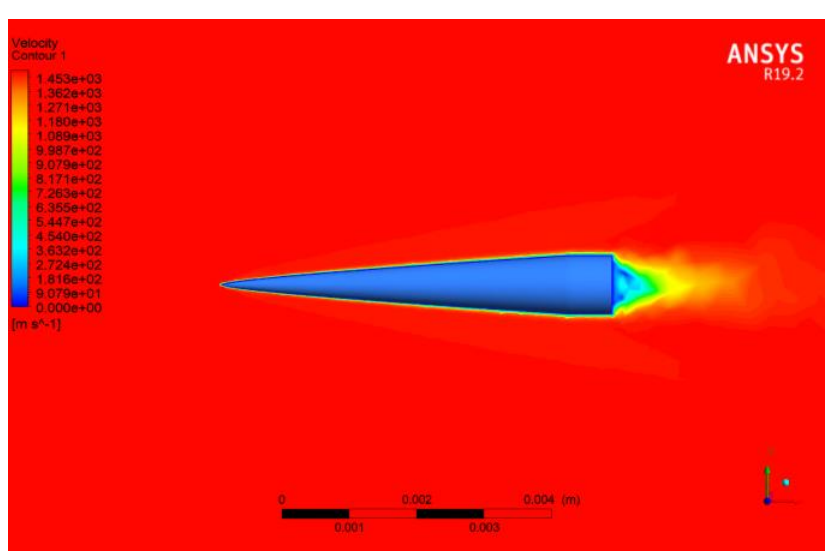

(a)

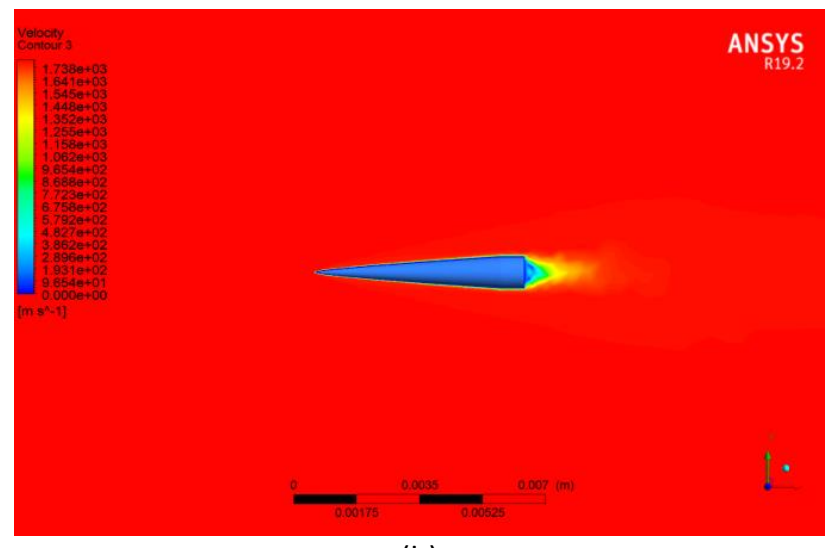

(b)

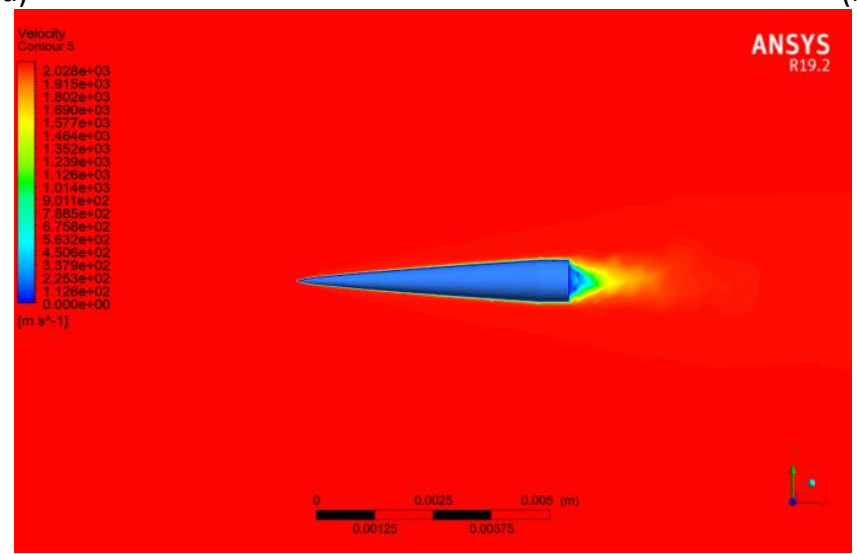

(c)

Fig. 6. Velocity flow contours at (a) Mach number 5 (b) Mach number 6 and (c) Mach number 7

\subsection{Improved Result Analysis}

As the study is done for Mach number ranges from 5 to 10, all the cases' results are compared and analyzed in this section which helps to get an improved result. The increase of density with the increasing Mach number for all the Mach cases and zero AOA are presented in Figure 7. When the Mach number increases the high density of the nose point spreads to the quarter portion of the projectile. The red lines in the figures represent the changes. The maximum pressures at different Mach numbers, $9.09 \times 10^{\wedge} 5 \mathrm{~Pa}, 1.102 \times 10^{\wedge} 6 \mathrm{~Pa}, 1.317 \times 10^{\wedge} 6 \mathrm{~Pa}$ for Mach numbers $8,9,10$ respectively are shown in Figure 8 . The lowest pressure can be seen at the bottom of the projectile. Figure 9 illustrates the free stream velocity at different Mach number as well as the reduction of shock angles for each case was also identified. Investigating the 10 cases the Mach 5, 6, and 7 cases are found to give better results among which the acceptable results of flow simulation are likely to be achieved at Mach 7. 


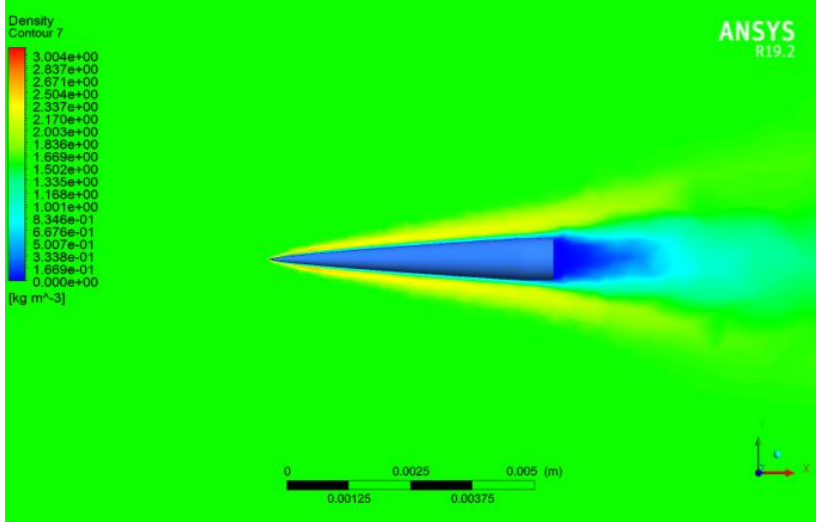

(a)

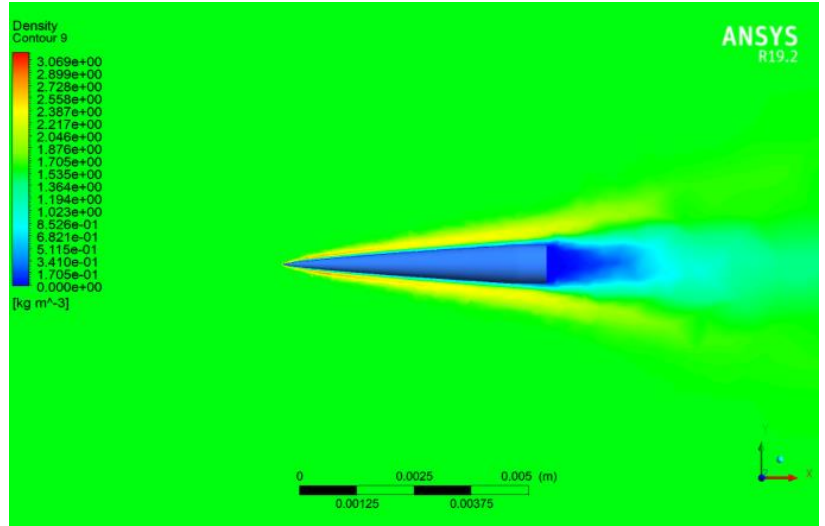

(b)

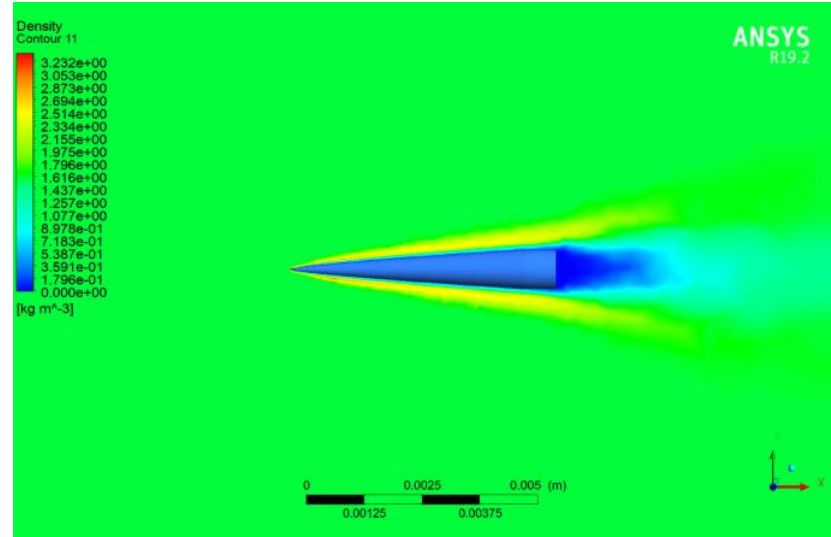

(c)

Fig. 7. Density flow contours at (a) Mach number 8 (b) Mach number 9 and (c) Mach number 10

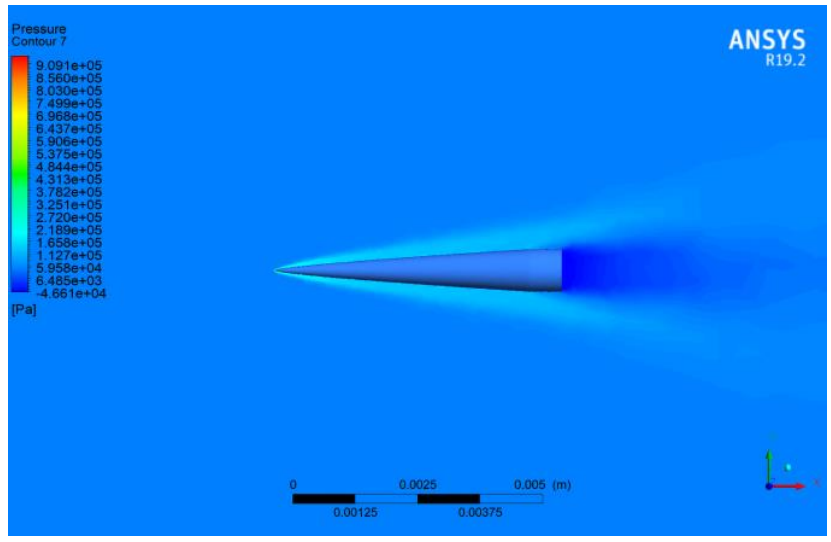

(a)

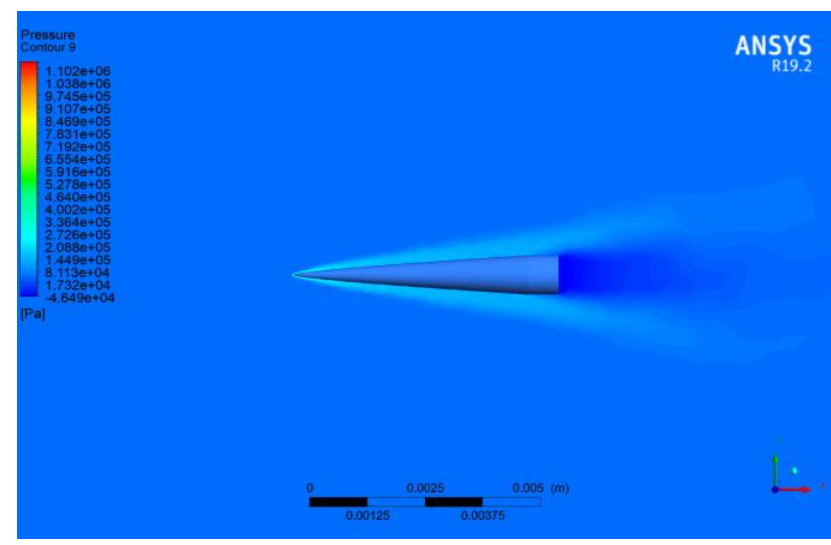

(b)

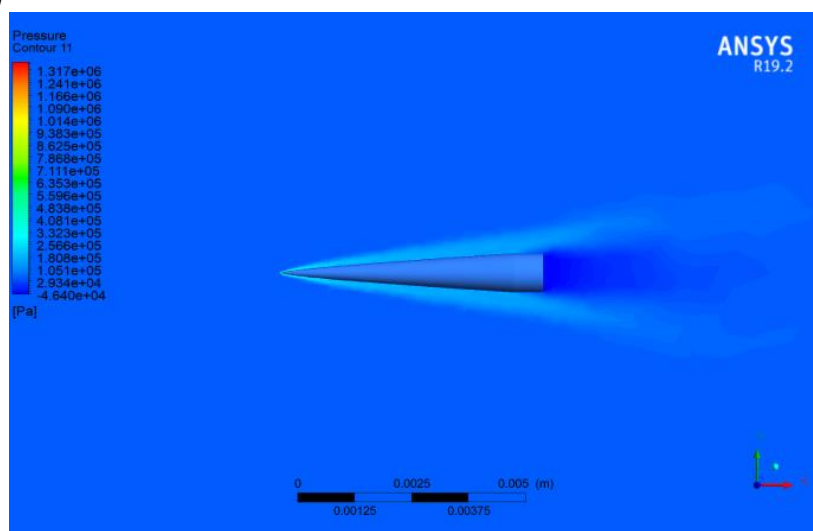

(c)

Fig. 8. Pressure flow contours at (a) Mach number 8 (b) Mach number 9 and (c) Mach number 10 


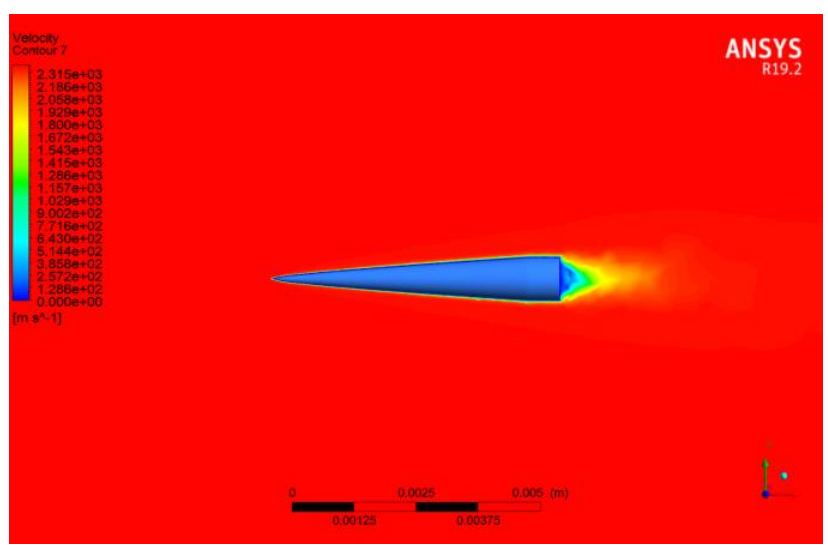

(a)

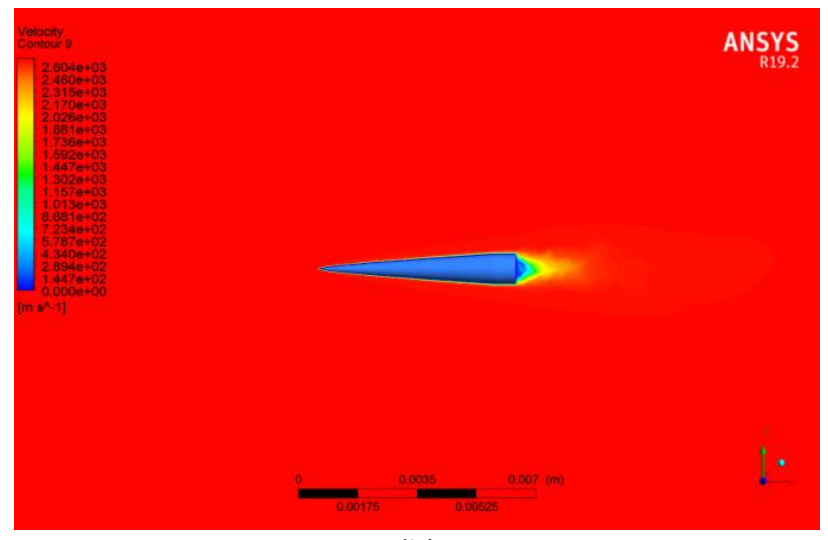

(b)

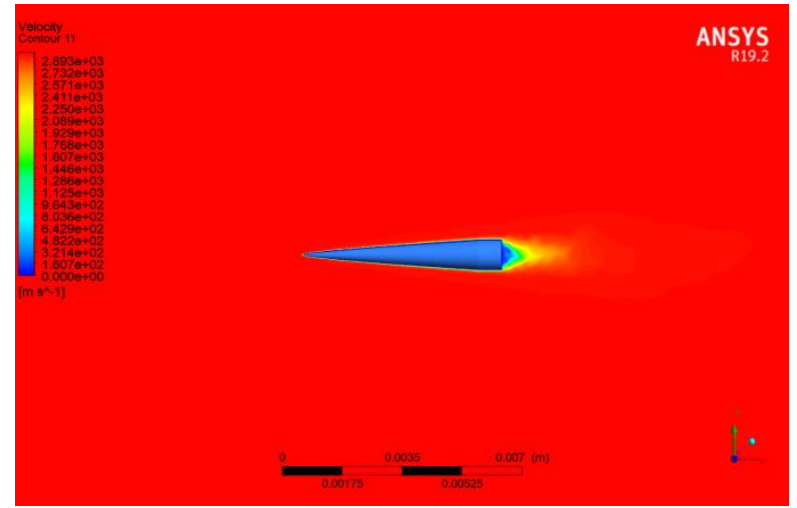

(c)

Fig. 9. Velocity flow contours at (a) Mach number 8 (b) Mach number 9 and (c) Mach number 10

\subsection{Grid Independence Test Results}

In this section, the results which are obtained from the grid independence test are discussed. The grid independence test was undertaken for various mesh element sizes at Mach number 7 and zero AOA. Here the Figure 10 explains the changes in density flow contours when the element size was changed making it as 5.4169e-3 m, 2.43e-3 m, 2.853e-3 m, and $1.9853 \mathrm{e}-3 \mathrm{~m}$ at Mach 7. These figures show that the increase in density while decreasing the mesh element size. Gradually, for the smallest element size, the density around the nose of the projectile was found to be lowest comparing with the other cases. The shock was also less dense than others.

The differences in pressure-flow contours are shown in the Figure 11 which describes that with the decrease of grid size pressure around the baseline and the maximum pressure was increased remarkably at Mach number 7 . Among the cases for the grid size $2.43 \mathrm{e}-3 \mathrm{~m}$, the numerical results show comparatively well harmony with the experimental results at Mach number 7 and zero angles of attack. The variation in velocities for different grid sizes at Mach 7 is shown in the Figure 12 it can be seen that there was some minor change in velocities found and the largest velocity was 6 found when the element size was $2.43 \mathrm{e}-3 \mathrm{~m}$. The visual explanation of the variation of the velocity can be found in Figure 13. 


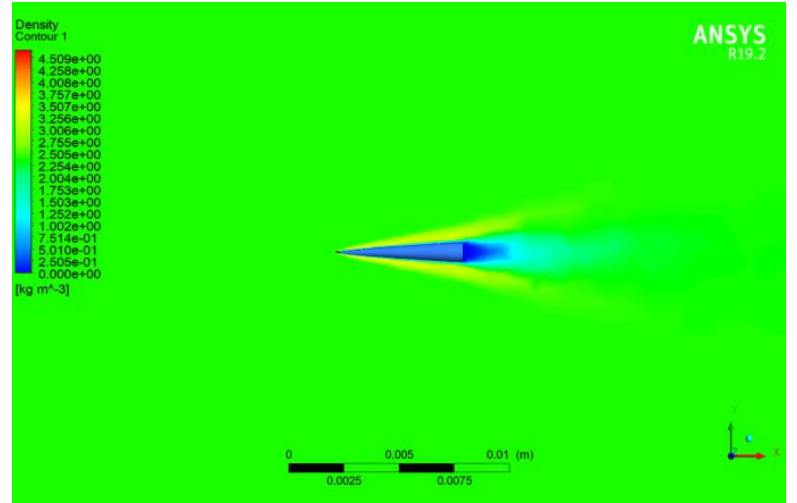

(a)

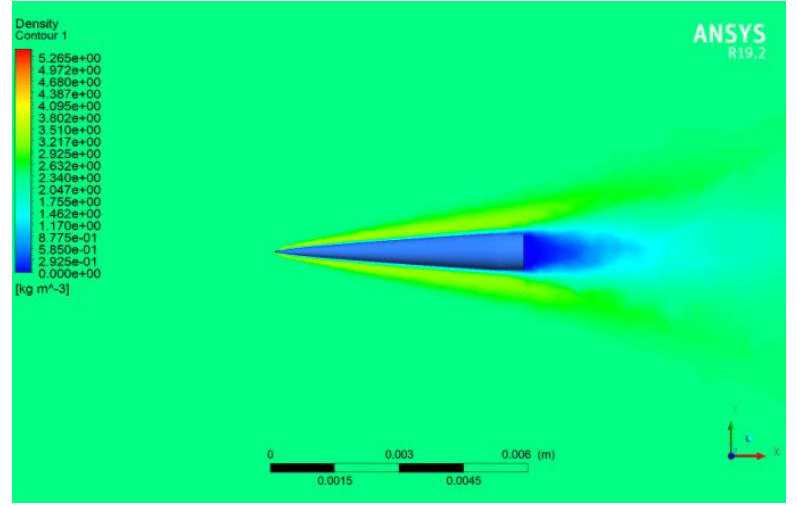

(c)

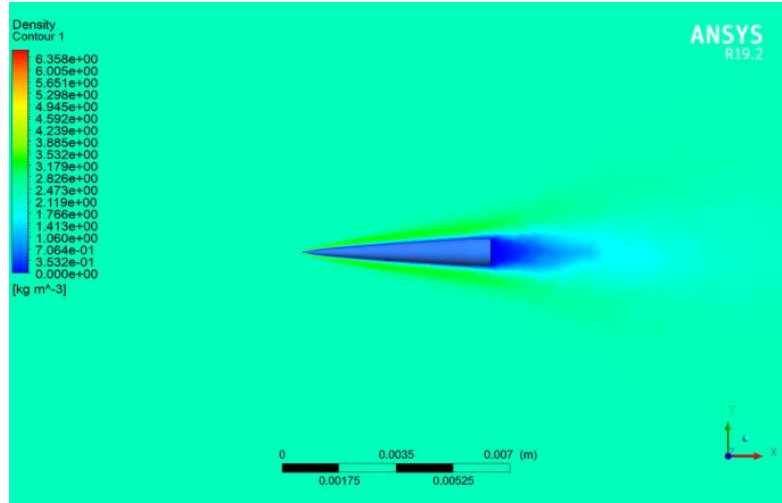

(b)

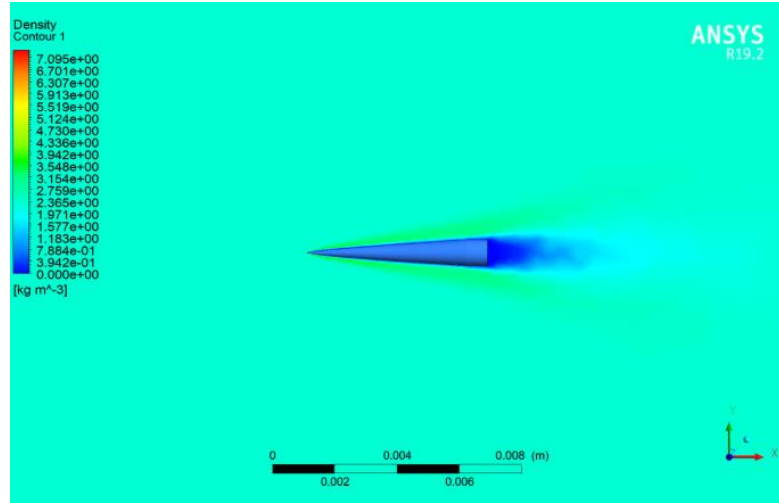

(d)

Fig. 10. Density flow contour for (a) mesh element size $5.4169 \mathrm{e}-3 \mathrm{~m}$ at Mach number 7 (b) mesh element size 2.43e-3 $\mathrm{m}$ at Mach number 7 (c) mesh element size 2.853e-3 $\mathrm{m}$ at Mach number 7 and (d) for mesh element size $1.9853 \mathrm{e}-3 \mathrm{~m}$ at Mach number 7

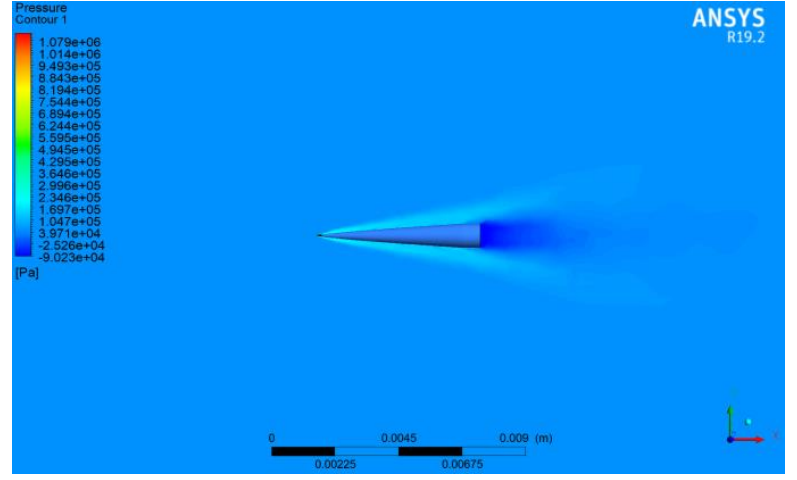

(a)

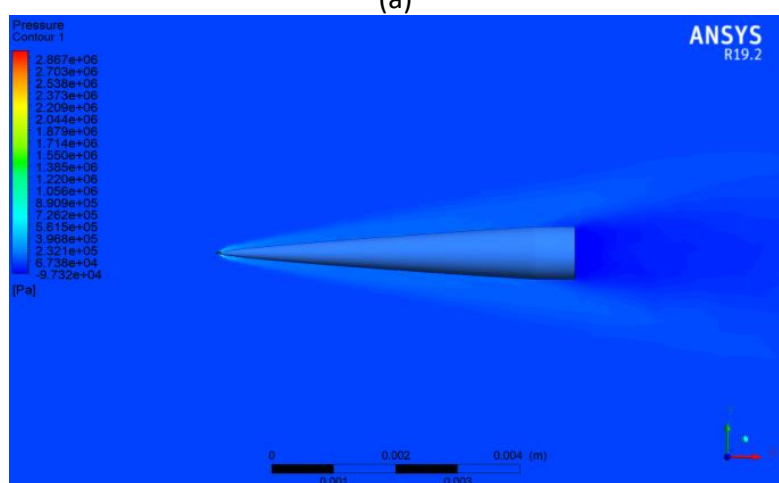

(c)

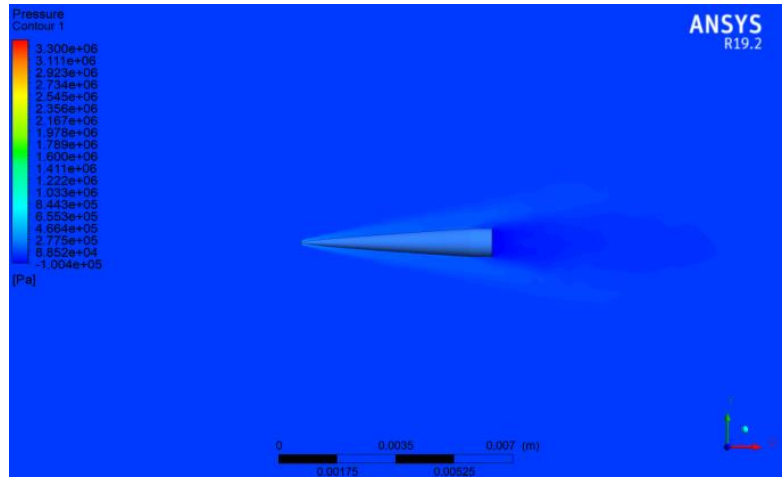

(b)

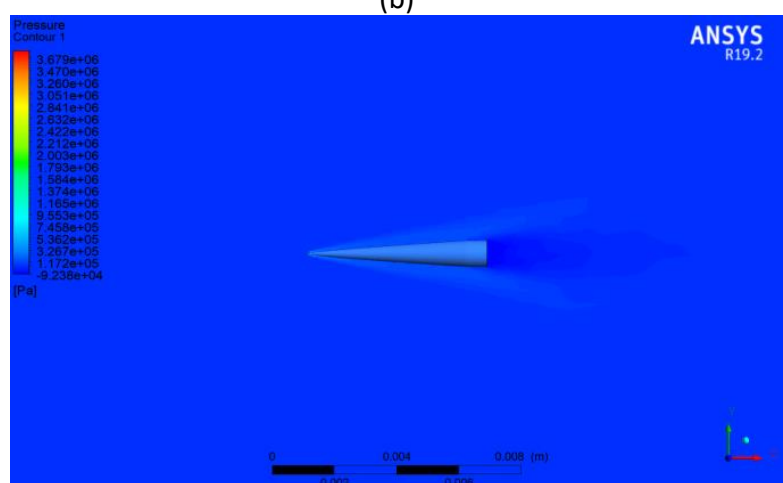

(d)

Fig. 11. Pressure flow contour for (a) mesh element size $5.4169 \mathrm{e}-3 \mathrm{~m}$ at Mach number 7 (b) mesh element size 2.43e-3 m at Mach number 7 (c) mesh element size 2.853e-3 m at Mach number 7 and (d) for mesh element size $1.9853 \mathrm{e}-3 \mathrm{~m}$ at Mach number 7 


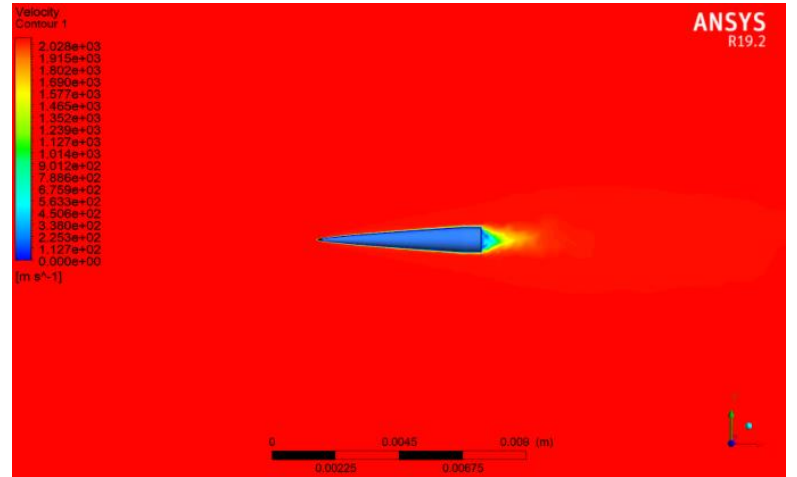

(a)

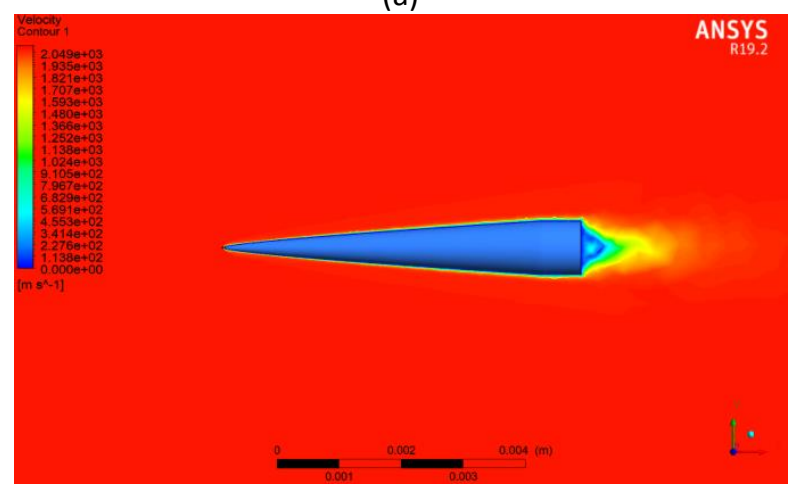

(c)

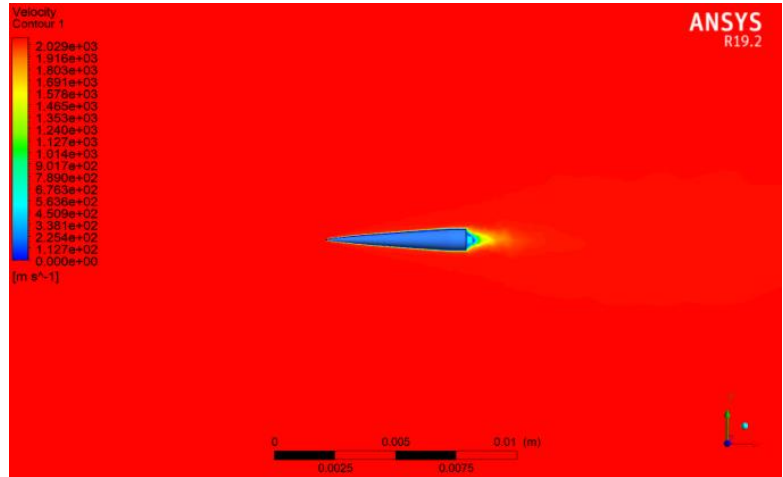

(b)

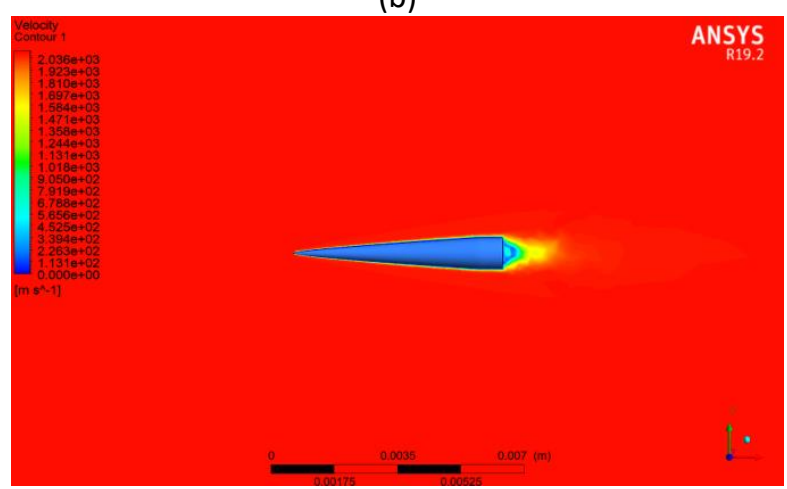

(d)

Fig. 12. Velocity flow contour for (a) mesh element size $5.4169 \mathrm{e}-3 \mathrm{~m}$ at Mach number 7 (b) mesh element size $2.43 \mathrm{e}-3 \mathrm{~m}$ at Mach number 7 (c) mesh element size $2.853 \mathrm{e}-3 \mathrm{~m}$ at Mach number 7 and (d) for mesh element size 1.9853e-3 $\mathrm{m}$ at Mach number 7

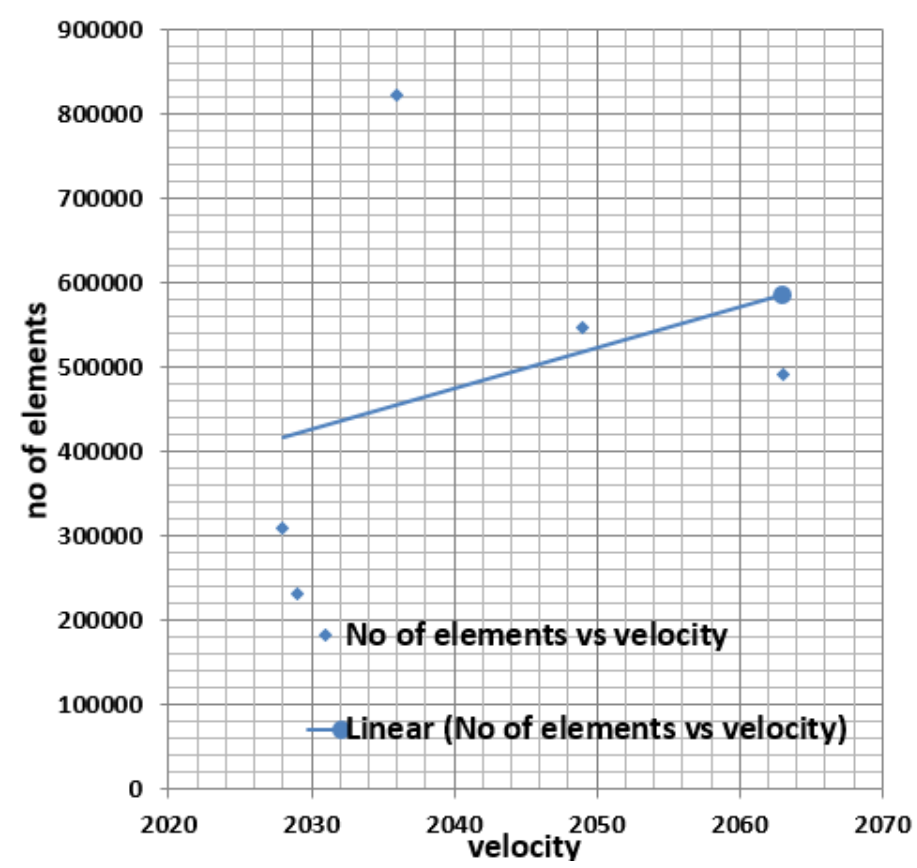

Fig. 13. Variation of velocity with the changing mesh element size at Mach number-7 and zero AOA 


\subsection{Turbulence Models Results}

In order to get more accurate results especially for wall functions $[\mathrm{Y}+]$, this test was undertaken using four turbulence models namely Spalart Allmaras model, K-epsilon [releasable], K-omega and Large Eddy Simulation, etc. In this section, the results obtained from these turbulence models tests are analyzed.

The most common one equation Spalart Allmaras turbulence model is extensively used for aerospace industrial purposes because it gives good results for boundary layer separations. On the other hand, in the two-equation models, the K-epsilon gives the wall results far from boundaries and K-omega predicts results near the wall. LES works quite similarly to the SA model. Among these turbulence model tests, the SA and LES models show better performance to predict the boundary layer. But in comparing the SA and LES turbulence models results from the Spalart Allmaras model results a pretty well concurrence with the previously tested result. In Table 4 the variation of aerodynamic parameters was compared which were obtained from different turbulence model tests. It is shown that the SA turbulence model gives the best performance at Mach number 7 comparing with Mach number 5 and 6 cases.

The Figure 14 illustrates the flow contours of eddy viscosity, vorticity, and $Y$ plus of the projectile for the SA model at Mach number-7. By the figures, it can be seen clearly that there was an eddy viscosity area at the bottom and the nose of the projectile, as well as the vorticity area, was at the bottom of the projectile. Figure 15 describes that the increase in $\mathrm{Y}+$ caused the tangential velocity to decrease. By the whole analysis, it is transparent that the SA turbulence model gives the best aerodynamic behaviors at Mach 7 amongst the others.

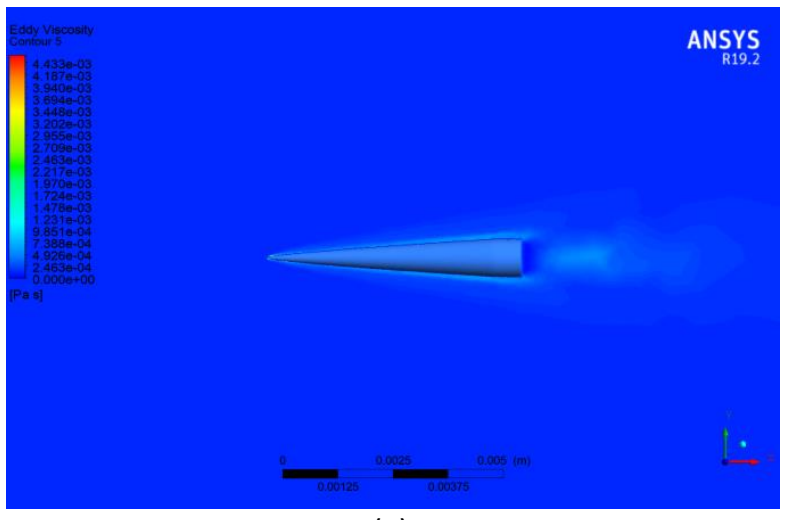

(a)

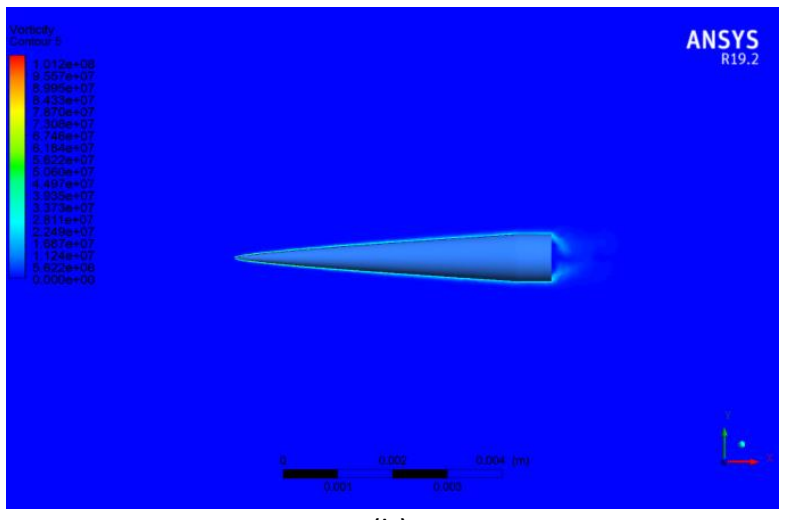

(b)

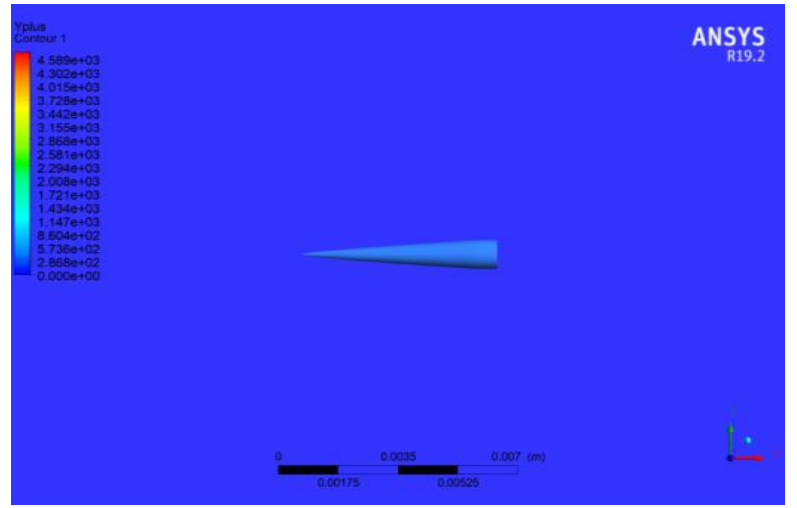

(c)

Fig. 14. (a) Flow contours of Eddy viscosity at Mach number 7 using SA turbulence model (b) Flow contours of vorticity at Mach number 7 using SA turbulence model (c) Y+ at Mach number 7 using SA turbulence model 


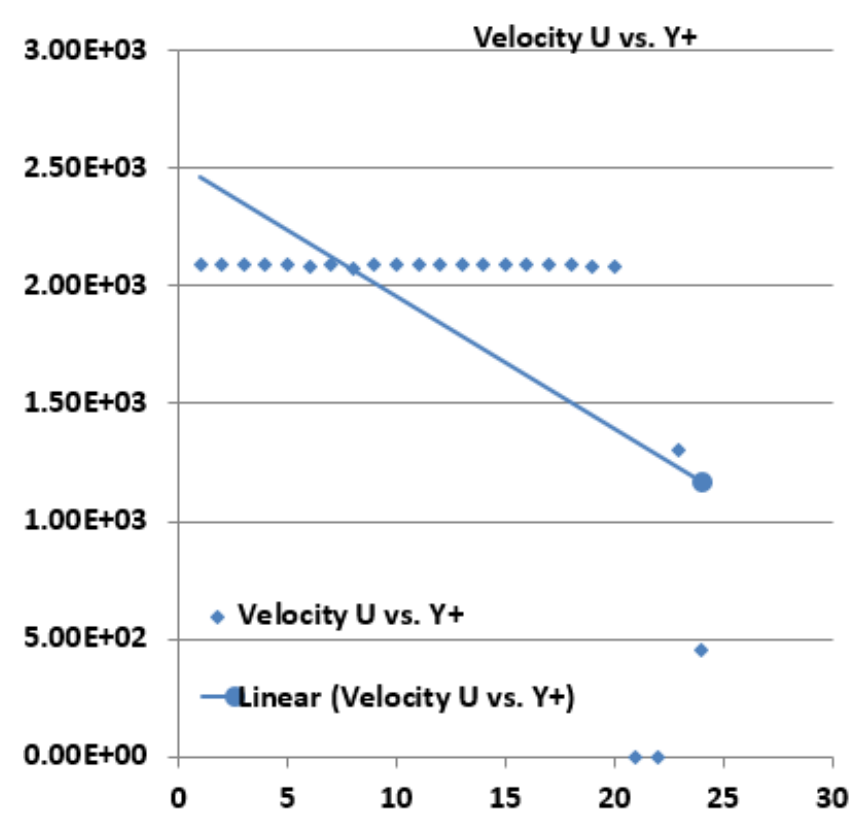

Fig. 15. $U$ vs. $Y+$ chart for Spalart Allmaras model at Mach number

\section{Table 4}

Represents the variation of aerodynamics parameters at different Mach number and for different turbulence model

\begin{tabular}{|c|c|c|c|c|c|}
\hline \multicolumn{2}{|c|}{ Parameters $\backslash$ models } & \multirow{2}{*}{$\begin{array}{l}\text { Spalart Almaras } \\
\text { (SA) } \\
3.011\end{array}$} & \multirow{2}{*}{$\begin{array}{l}\text { K-epsilon } \\
4.518\end{array}$} & \multirow{2}{*}{$\begin{array}{l}\text { K-omega } \\
4.482\end{array}$} & \multirow{2}{*}{$\begin{array}{l}\text { Large Eddy Simulation(LES) } \\
\text { Mach number-5 }\end{array}$} \\
\hline Mach number-5 & $\begin{array}{l}\text { Density } \\
{[\max ] \mathrm{kg} / \mathrm{m}^{\wedge} 3}\end{array}$ & & & & \\
\hline & Pressure [max] & $4.633 e+05$ & $6.37 e+05$ & $6.473 e+05$ & \\
\hline & $\mathrm{Pa}$ & & & & \\
\hline & Velocity [max] $\mathrm{m} / \mathrm{s}$ & 1453 & 1448 & 1448 & \\
\hline \multirow[t]{3}{*}{ Mach number- 6} & $\begin{array}{l}\text { Density } \\
{[\max ] \mathrm{kg} / \mathrm{m}^{\wedge} 3}\end{array}$ & 3.040 & 4.501 & 4.499 & Mach number- 6 \\
\hline & $\begin{array}{l}\text { Pressure } \\
{[\mathrm{max}] \mathrm{Pa}}\end{array}$ & $5.965 e+05$ & $8.213 e+05$ & $8.667 e+05$ & \\
\hline & $\begin{array}{l}\text { Velocity } \\
{[\max ] \mathrm{m} / \mathrm{s}}\end{array}$ & 1738 & 1742 & 1736 & \\
\hline \multirow[t]{3}{*}{ Mach number-7 } & $\begin{array}{l}\text { Density } \\
{[\max ] \mathrm{kg} / \mathrm{m}^{\wedge} 3}\end{array}$ & 3.008 & 4.461 & 4.491 & Mach number-7 \\
\hline & Pressure [max] $\mathrm{Pa}$ & $7.388 \mathrm{e}+05$ & $1.033 e+06$ & $1.034 \mathrm{e}+06$ & \\
\hline & $\begin{array}{l}\text { Velocity } \mathrm{m} / \mathrm{s} \\
{[\max ]}\end{array}$ & 2028 & 2675 & 1991 & \\
\hline
\end{tabular}

\section{Conclusion}

In this study, it was desired to enhance and understand the aerodynamic performance of a hypersonic EM gun projectile in a better way. With the help of numerical techniques, it was demonstrated that the visual simulation of railgun projectile acted a better performance during flight. 


\subsection{Baseline Analysis}

At first, the test was conducted for Mach number 5 and specific boundary conditions which resulted in the density, Maximum pressure, and velocity as $3.011 \mathrm{~kg} / \mathrm{m}^{3}, 4.667 \times 10^{5} \mathrm{~Pa}$ and 1453 $\mathrm{m} / \mathrm{s}$. To get a better understand the test was conducted several times differing the Mach numbers, grid sizes, turbulence models, etc. By analyzing the results, it is found that the projectile gives better performance for the Mach cases 5, 6, 7 showing a good simulation of flow contours in comparison with the Mach umber cases ranges from 8 to 10. In these results it is presented by the flow contours that the flow around the baseline has a good harmony with the experimental results as density around the baseline is found low and the pressure at the nose is found maximum for each case. But it is proved by some variation among the flow contours for Mach 5, 6, and 7 that a better performance aerodynamic behaviors of the projectile can be found at Mach 7 having density around baseline $2.17 \mathrm{~kg} / \mathrm{m}^{3}$, the pressure at nose $2.15 \mathrm{e}+5 \mathrm{~Pa}$, and the highest velocity of $2028 \mathrm{~m} / \mathrm{s}$. Whereas, the other cases show poor performance on velocity contours. For the Mach number ranges from 8-10 the flow contours are found poor having a smaller shock angle, high density, and pressure that can affect the performance of the projectile during flight.

\subsection{Performance Improvement Through Varying the Mach Numbers}

By analyzing the results obtained from different Mach cases it can be said that the Mach number ranges from 8-10 give high velocity as well as higher density and pressure. An excessive amount of pressure and density can increase the drag that affects the flight of the projectile. In compressible flow, the high speed of the projectile causes an increase in density and pressure also. By the results, it is found that at Mach 10 the speed is found $3400 \mathrm{~m} / \mathrm{s}$, as well as the density and pressure, are found to be $3.23 \mathrm{~kg} / \mathrm{m}^{\wedge} 3$ and $1.32 \mathrm{e}+06 \mathrm{~Pa}$ respectively. The high density and pressure decrease flight stability. Moreover, for Mach 7 the flow contours of density, pressure, velocity, viscosity, etc. show the best results having the least validation error. In this case, the error of velocity, density, and pressure are found as $0.049 \%,-399 \%$, and $-86 \%$. Whereas, the results for Mach 5 and 6 are less appropriate. Therefore, it is proven that for Mach number 7 the projectile performs very well giving less error.

\subsection{Performance Improvement Through Grid Independence Check}

Analyzing the grid independence results for different grid sizes at Mach 7 and zero AOA, it is found that for the smallest grid size of $1.254 \mathrm{e}-3 \mathrm{~m}$ the flow contour of density, pressure, and velocity show better results containing maximum density $4.49 \mathrm{~kg} / \mathrm{m}^{\wedge} 3$ but larger pressure and velocity. For this grid, the obtained density is the smallest having less error compared to the other cases. Whereas, for the grid size $2.43 \mathrm{e}-3 \mathrm{~m}, 2.853 \mathrm{e}-3 \mathrm{~m}$, and $1.9853 \mathrm{e}-3 \mathrm{~m}$ the flow contours results are poor having larger errors. But overall a better performance is obtained from grid independence test for mesh element size $5.4169 \mathrm{e}-3 \mathrm{~m}$ where the maximum density, pressure, and velocity are found to be $4.509 \mathrm{~kg} / \mathrm{m}^{3}, 1.079 \mathrm{e}+6 \mathrm{~Pa}$ and $2028 \mathrm{~m} / \mathrm{s}$ respectively having least validation errors. For this test, the validation errors for the density, pressure, and velocity are obtained as follows $650.249 \%,-171.65 \%$, and $0.068 \%$ respectively. Therefore, by the grid independence check it is proven that for mesh element size $5.4169 \mathrm{e}-3 \mathrm{~m}$ at Mach-7 and zero AOA the results are more acceptable for the aerodynamics analysis of EM gun projectile. 


\subsection{Performance Improvement Through Different Turbulence Models}

To predict the better performance of the EM gun projectile during flight CFD numerical test was conducted again for different turbulence models also. For Mach 5, 6, and 7 the density 4.48 $\mathrm{kg} / \mathrm{m}^{\wedge} 3,4.499 \mathrm{~kg} / \mathrm{m}^{\wedge} 3$, and $4.491 \mathrm{~kg} / \mathrm{m}^{\wedge} 3$ respectively having larger errors are achieved from the two-equation turbulence models K-e [realizable] and K-w test. Similarly, using these two models very low velocities are found for Mach numbers 5, 6, and 7 having some unexpected errors. In pressure-flow contours similarity between the two models' results are noticed and a very poor result is obtained. Additionally, for large eddy simulation turbulence models high density for different Mach numbers is found. In this case, density errors for Mach 5, 6, and 7 are -766.9\%, $656 \%$, and $-650 \%$ found which gives poor agreement with the experimental results. Besides only Mach 7 the LES model gives a high velocity of $2028 \mathrm{~m} / \mathrm{s}$ and the least velocity error of $0.069 \%$. Whereas, the Spalart Allmaras model is used for Mach 5, 6, and 7 to get a better understand of the aerodynamic behaviors of the projectile. Using this one equation model the density at Mach 5, 6, and 7 are obtained as follows- $3.001 \mathrm{~kg} / \mathrm{m}^{\wedge} 3,3.0 \mathrm{~kg} / \mathrm{m}^{\wedge} 3$, and $3.000 \mathrm{~kg} / \mathrm{m}^{\wedge} 3$. The maximum pressure, temperature, and velocity are obtained from the Mach 7 test which are $7.388 \mathrm{e}+05 \mathrm{~Pa}$, $4.567 \mathrm{e}+03 \mathrm{k}$, and $2028 \mathrm{~m} / \mathrm{s}$ respectively. By this SA turbulence model test for Mach number 7, the least error is found which is $0.01 \%$ for velocity as well as for density and pressure the errors are $399 \%$ and $-86.09 \%$ respectively. Moreover, the wall function for this test also shows a better result. Large vorticity is also found at the bottom of the projectile due to high velocity. Overall it can be said that the Spalart Allmaras model can help to conduct the test more accurately.

By the whole analysis, it is proved that the EM gun projectile gives a better performance at Mach number 7 and this can be understood using the SA one equation turbulence model for $5.4169 \mathrm{e}-3 \mathrm{~m}$ mesh element size. The above-mentioned requirements conduct the test properly giving the expected results. The experiment would be more accurate if it could be conducted on a supercomputer in a lab instead of Intel[R] Core[TM] i5-104000 CPU $2.90 \mathrm{GHz}$ computer.

\section{Acknowledgment}

I would like to express my very great appreciation to my research supervisor Prof: Srinivas G. Assistant Professor (Sr Scale) for his valuable and constructive suggestions during the work. I am very much thankful for his guidance, enthusiastic encouragement, and useful critiques of this research work. I would also like to thank IAESTE, LC Manipal, India for giving me such an amazing opportunity to achieve some technical experience during this Corona pandemic. It helps me to improve my research skills as well as technical skill.

\section{References}

[1] Shen, Jian, Shao-bo Fan, Ya-xin Ji, Qing-yu Zhu, and Ji Duan. "Aerodynamics analysis of a hypersonic electromagnetic gun launched projectile." Defence Technology (2020). https://doi.org/10.1016/i.dt.2020.01.008

[2] Ochieng, Victor. "What Is a Railgun? The Navy's Electromagnetic Weapon." Hostile, 3 June 2020.

[3] Suciu, Peter. "Navy Railguns Are Coming (And Could Shoot Massive Slugs at Mach 10)." The National Interest, The Center for the National Interest, 3 Oct. 2020.

[4] "Physics of a Railgun." Physics Stack Exchange, 1 July 1963.

[5] Ismail, Noor Iswadi, Zurriati Mohd Ali, Iskandar Shah Ishak, R. M. Noor, and Rosniza Rabilah. "Aerodynamic Performances of Paper Planes." Journal of Advanced Research in Fluid Mechanics and Thermal Sciences 77, no. 1 (2021): 124-131. https://doi.org/10.37934/arfmts.77.1.124131

[6] Tajuddin, Nurulhuda, Shabudin Mat, Mazuriah Said, and Shumaimi Mansor. "Flow characteristic of blunt-edged delta wing at high angle of attack." Journal of Advanced Research in Fluid Mechanics and Thermal Sciences 39, no. 1 (2017): 17-25. 
[7] Shen, Jian, Shao-bo Fan, Ya-xin Ji, Qing-yu Zhu, and Ji Duan. "Aerodynamics analysis of a hypersonic electromagnetic gun launched projectile." Defence Technology 16, no. $4 \quad$ (2020): $753-761$. https://doi.org/10.1016/j.dt.2020.01.008

[8] Young, David, and David Goldstein. "A study of unsteady hypersonic segmented projectile aerodynamics." In 14th Computational Fluid Dynamics Conference, p. 3379. 1999. https://doi.org/10.2514/6.1999-3379

[9] Xu, Lizhi, Chengxin Du, Chun Cheng, Xiaodong Wang, Jiangbo Wang, Zhonghua Du, and Guangfa Gao. "Effect of projectile parameters on opening behavior of PELE penetrating RC target." Defence Technology (2020). https://doi.org/10.1016/i.dt.2020.04.012

[10] Tang, Bo, Ying-tao Xu, Gang Wan, Jiang Yue, Yong Jin, and Hai-yuan Li. "Method of ballistic control and projectile rotation in a novel railgun." Defence Technology 14, no. 5 (2018): 628-634. https://doi.org/10.1016/i.dt.2018.07.022

[11] Weinacht, Paul. "Projectile performance, stability, and free-flight motion prediction using computational fluid dynamics." Journal of Spacecraft and Rockets 41, no. 2 (2004): 257-263. https://doi.org/10.2514/1.1037

[12] Naik, S. D. "A note on stability of motion of a projectile." Sadhana 26, no. 4 (2001): 379-385. https://doi.org/10.1007/BF02703407

[13] Sahu, Jubaraj. "CFD simulations of a finned projectile with microflaps for flow control." International Journal of Aerospace Engineering 2017 (2017). https://doi.org/10.1155/2017/4012731

[14] Weinacht, Paul, Walter B. Sturek, and Lewis B. Schiff. "Navier-stokes predictions of pitch damping for axisymmetric projectiles." Journal of Spacecraft and Rockets 34, no. $6 \quad$ (1997): 753-761. https://doi.org/10.2514/2.3306

[15] Sahu, Jubaraj. "Time-accurate numerical prediction of free-flight aerodynamics of a finned projectile." Journal of Spacecraft and Rockets 45, no. 5 (2008): 946-954. https://doi.org/10.2514/1.34723

[16] Yadav, Rajesh, and Ugur Guven. "Aerodynamic heating of a hypersonic projectile with forward-facing ellipsoid cavity at nose." Journal of Spacecraft and Rockets 52, no. 1 (2015): 157-165. https://doi.org/10.2514/1.A32605

[17] Maicke, Brian, Timothy Barber, and Joe Majdalani. "Evaluation of CFD codes for hypersonic flow modeling." In 46th AIAA/ASME/SAE/ASEE joint propulsion conference \& exhibit, p. 7184.2010. https://doi.org/10.2514/6.2010-7184

[18] Roy, Christopher J., and Frederick G. Blottner. "Methodology for turbulence model validation: application to hypersonic flows." Journal of spacecraft and rockets 40, no. 3 (2003): 313-325. https://doi.org/10.2514/2.3966

[19] Paciorri, R., W. Dieudonne, G. Degrez, J-M. Charbonnier, H. Deconinck, R. Paciorri, W. Dieudonne, G. Degrez, J-M. Charbonnier, and H. Deconinck. "Validation of the Spalart-Allmaras turbulence model for application in hypersonic flows." In 28th Fluid Dynamics Conference, p. 2023. 1997. https://doi.org/10.2514/6.1997-2023

[20] Deck, Sébastien, Philippe Duveau, Paulo d'Espiney, and Philippe Guillen. "Development and application of Spalart-Allmaras one equation turbulence model to three-dimensional supersonic complex configurations." Aerospace science and technology 6, no. 3 (2002): 171-183. https://doi.org/10.1016/S12709638(02)01148-3

[21] Anderson Jr, John D. Hypersonic and high-temperature gas dynamics. American Institute of Aeronautics and Astronautics, 2006. https://doi.org/10.2514/4.861956

[22] Deck, Sébastien, Philippe Duveau, Paulo d'Espiney, and Philippe Guillen. "Development and application of Spalart-Allmaras one equation turbulence model to three-dimensional supersonic complex configurations." Aerospace science and technology 6, no. 3 (2002): 171-183. https://doi.org/10.1016/S1270$\underline{9638(02) 01148-3}$ 